\title{
TEMAS SOCIOCIENTÍFICOS (CERVEJA) EM AULAS PRÁTICAS DE QUÍMICA NA EDUCAÇÃO PROFISSIONAL: UMA ABORDAGEM CTS
}

\begin{abstract}
Míriam Stassun dos Santos
Química, licenciada e bacharel (UFMG), Mestre em Tecnologia - Educação Tecnológica (CEFET-MG/UFMG), Doutoranda em Ensino de Ciências e Matemática da Universidade Cruzeiro do Sul (UNICSUL). Atualmente docente do Departamento de Química do CEFET-MG. miriamstassun@gmail.com

Carmem Lúcia Costa Amaral

Química (UFRN), Mestrado e Doutorado em Química Orgânica (USP), docente e pesquisadora do Programa de Doutorado e Mestrado em Ensino de Ciências e Matemática da Universidade Cruzeiro do Sul (UNICSUL). carmem.amaral@ cruzeirodosul.edu.br

\section{Maria Delourdes Maciel}

Ciências Biológicas (UFRGS), Mestrado, Doutorado e Pós-doutorado em Educação (PUCSP), docente e pesquisadora do Programa de Doutorado e Mestrado em Ensino de Ciências e Matemática da Universidade Cruzeiro do Sul - UNICSUL. delourdes.maciel@ gmail.com
\end{abstract}

\section{RESUMO}

Apresentaremos resultados de uma pesquisa qualitativa, método "estudo de caso", com observação sistemática durante as aulas práticas de Química Orgânica Aplicada, que adotou como programa curricular, alguns temas sociocientíficos (TS) com enfoque Ciência, Tecnologia e Sociedade - CTS. Participaram alunos do $3^{\underline{0}}$ ano do ensino profissional técnico de Química integrado ao ensino médio, do CEFET-MG. Produzimos dados partindo de questionários (inclusive o internacional - PIEATCTS), anotações, aulas gravadas e filmagens. Consideramos como pressupostos básicos a centralidade no trabalho prático, a percepção dos alunos sobre abordagem metodológica, o desenvolvimento de atitudes, valores e habilidades. Evidenciamos a importância da formação e da experiência do professor conduzindo as discussões, o aumento de interações dialógicas e a promoção de situações vivenciais dos alunos, principalmente em relação às atitudes e aos valores. Os resultados apontaram a importância de adotar estratégias envolvendo alunos em discussões de temas reais, e a inserção de TS nos currículos do ensino profissional técnico de Química de nível médio, como condições fundamentais para o alcance do objetivo da formação da cidadania. E ainda, mostraram o enfoque CTS, como fonte fecunda para a análise do processo educacional das áreas técnicas, com potencialidades transformadoras, para cursos que visem à alfabetização científica na perspectiva humanística, reflexiva e crítica.

PALAVRAS-CHAVE: Educação profissional, Temas sociocientíficos, CTS, PIEARCTS. 


\title{
SUBJECTS SOCIOCIENTÍFICOS (BEER) IN PRACTICAL LESSONS OF CHEMISTRY IN THE PROFESSIONAL EDUCATION: A BOARDING CTS
}

\begin{abstract}
We will present results of a qualitative research, method "case study", with systematic comment during the practical lessons of Applied Organic Chemistry, that it adopted as curricular program, some sociocientíficos subjects (TS) with approach Science, Technology and Society - CTS. They had participated to the 30 pupils of year of professional education technician of Chemistry integrated to average education, of the CEFET-MG. We produce data leaving of questionnaires (also the International PIEATCTS), recorded notations, lessons and filmings. We consider as estimated basic the centralidade in the practical work, the perception of the pupils on metodológica boarding, the development of attitudes, values and abilities. We evidence the importance of the formation and the experience of the professor leading the quarrels, the increase of dialógicas interactions and the promotion of existential situations of the pupils, mainly in relation to the attitudes and the values. The results had pointed the importance to adopt strategies involving pupils in quarrels of real subjects, and the insertion of TS in the resumes of professional education technician of Chemistry of average level, as basic conditions with respect to the reach of the objective of the formation of the citizenship. E still, had shown approach CTS, as fruitful source for the analysis of the educational process of the areas techniques, with transforming potentialities, for courses that they aim at to the scientific alfabetização in the humanistic perspective, reflexiva and critical.
\end{abstract}

KEYWORDS: Professional Education, themes sociocientíficos, CTS, PIEARCTS. 


\section{TEMAS SOCIOCIENTÍFICOS (CERVEJA) EM AULAS PRÁTICAS DE QUÍMICA NA EDUCAÇÃO PROFISSIONAL: UMA ABORDAGEM CTS}

\section{INTRODUÇÃO}

A pesquisa é qualitativa e utilizou como método o "estudo de caso". As observações foram realizadas nas aulas da disciplina de Química Orgânica Aplicada, totalmente experimental, onde se adotou como programa, oito temas sociocientíficos (TS) com enfoque CTS. Esta pesquisa foi desenvolvida em uma turma da $3^{\underline{a}}$ série do ensino profissional técnico de Química integrado ao ensino médio no Departamento de Química, do CEFET-MG, Campus I, Belo Horizonte/MG. A instituição federal e centenária há mais de quarenta anos oferece cursos técnicos em Química e há cinco, curso de bacharelado em Química.

O professor escolhido foi aquele que apresentou, no relato do desenvolvimento de suas aulas, mais relações com esquemas conceituais e metodológicos que contemplavam as características do enfoque CTS. Possuía formação de bacharelado e licenciatura em Química, doutorado em Ciências, dez anos de experiência em ensino de Química e em Alimentos, no ensino técnico e na graduação e integrava a linha de pesquisa de Química Orgânica Tecnológica: biotecnologia; biodiesel; alimentos e bebidas.

$\mathrm{Na}$ pesquisa proposta buscamos focalizar: a) a centralidade no trabalho prático desenvolvido a partir de temas sociocientíficos (TS) com enfoque CTS; b) as interações em sala de aulas práticas; c) as atitudes e os valores dos alunos frente à Ciência, Tecnologia e Sociedade; e d) a didática do professor de Química. Para o seu desenvolvimento usou-se os procedimentos de observação das aulas práticas, registros em caderno de campo, entrevistas, questionários (inclusive a versão brasileira do COCTS, o PIEARCTS), gravações e filmagens.

\section{CONTEXTUALIZAÇÃO DO PROBLEMA E REFERENCIAL TEÓRICO}

Alfabetizar alunos em ciência e tecnologia é hoje uma necessidade do mundo contemporâneo. Não se trata de mostrar maravilhas da ciência, mas de disponibilizar as representações que permitam ao cidadão agir, tomar decisão e compreender o que está em jogo no discurso dos especialistas (FOUREZ, 2003). Para isso é esperado que o aluno consiga fazer relações entre os conhecimentos científicos além da sala de aula, buscando compreender a dimensão social da ciência e da tecnologia, tanto do ponto de vista de seus antecedentes sociais como de suas conseqüências sociais e ambientais (VIEIRA e MARTINS, 2009).

De acordo com ACEVEDO et al. (2003), uma boa alternativa para a contribuição da escola à alfabetização científica e tecnológica é a introdução das relações entre Ciência, Tecnologia e Sociedade (relações CTS) nas aulas de Ciências. Para LÓPEZ e CEREZO (1996), trabalhar os conteúdos científicos segundo CTS significa ensinar os conteúdos no contexto autêntico do seu meio tecnológico e social, no qual os estudantes integram o conhecimento científico com a tecnologia e o mundo social de suas experiências do dia-adia. A proposta curricular envolvendo as relações CTS, apontada pela autora principal em 1999, corresponde assim, a uma integração entre educação científica, tecnológica e social, em que os conteúdos científicos e tecnológicos são estudados juntamente com a discussão de seus aspectos históricos, éticos, políticos, sociais, econômicos e ambientais. 
Buscando enfatizar o desenvolvimento da capacidade de tomada de decisão consciente e negociada que envolva ciência e tecnologia, apontada por Linsingen (2007), os currículos com enfoque CTS devem ser organizados em torno de temas sociais e as estratégias de ensino recomendadas são centradas na participação efetiva dos alunos. Os temas são explorados com caráter multidisciplinar e os conceitos são abordados em uma perspectiva relacional, evidenciando as diferentes dimensões do conhecimento estudado. Os autores SANTOS e MORTIMER (2003, 2009) mostram a abordagem de temas sociocientíficos no ensino de Ciências, com objetivo de desenvolver atitudes e valores em uma perspectiva humanística. Nessa mesma linha têm trabalhado outros pesquisadores, como: AULER (2003); AULER e DELIZOICOV (2001); COELHO e MARQUES (2007), buscando incorporar ao currículo discussões de valores e reflexões críticas que possibilitem desvelar a condição humana, ou seja, uma educação em que os alunos possam refletir sobre sua condição no mundo frente aos desafios postos pela ciência e tecnologia.

RAMSEY (1993) defende que para um tema propiciar uma discussão que gere um compromisso social é importante que ele tenha um significado real para o aluno. Para esse pesquisador é a partir da discussão de temas reais e da tentativa de delinear soluções para os mesmos que os alunos se envolvem de forma significativa e assumem um compromisso social. Uma das maneiras de discutir temas reais nas aulas de Ciências, em especial nas aulas de química, é por meio da experimentação, segundo YAGER (1991).

Assim, nesta pesquisa, buscamos observar se adotar no ensino profissional técnico de nível médio aulas práticas centradas em temas sociocientíficos, com ênfase nas relações CTS, levaria a uma alfabetização científica e tecnológica mais efetiva, geraria compromisso social, propiciaria a discussão dos aspectos históricos, éticos, políticos, sociais, econômicos e ambientais.

\section{DESENVOLVIMENTO DA PESQUISA}

Para a disciplina Química Orgânica Aplicada, totalmente experimental, organizamos o programa em torno de oito temas sociocientíficos (TS) e utilizamos estratégias de ensino centradas nas orientações CTS e na participação efetiva do aluno. No início do semestre, o professor apresentou vários TS aos alunos e, em duplas, escolheram aqueles que lhes parecia mais significativo, ou seja, Mel (Santos, 2010), Leite, Cerveja, Cachaça, Detergente, Sabão, Gasolina e Óleo Diesel. Bem no início do semestre, aplicamos um questionário $(\mathrm{Q} 1)$ buscando caracterizar os alunos que participavam deste estudo de caso.

Após a definição dos temas sociocientíficos, cada dupla trouxe para o laboratório uma amostra referente a cada tema estudado, a cada início de bloco de análise. Essas amostras são trazidas de locais próximos de onde moram, ou de marcas que têm curiosidade de verificar a qualidade e eles se apropriam dessas amostras e para eles, elas tornam-se reais. Para esses TS realizaram o controle de qualidade das amostras. Levando-se em consideração os equipamentos e o tempo de aulas - 150 minutos/semanais durante 20 semanas -, professor apresentou as análises gerais e os alunos decidiram quais seriam àquelas que eles consideravam as mais significativas, sendo que essa decisão era compartilhada com o professor. Em seguida, em duplas, os alunos planejaram o cronograma de execução, elaboraram fluxogramas e discutiram a proposta de redução e de tratamento dos resíduos gerados. Esses trabalhos eram apresentados ao professor e discutidos, separadamente, com cada dupla o seu desenvolvimento. Para cada TS as 
análises foram desenvolvidas por todas as seis duplas de alunos, em cerca de três semanas cada uma, para a amostra trazida.

Durante as aulas experimentais foram promovidas discussões, na tentativa de delinear soluções para os problemas identificados, gerados ou trazidos pelos alunos e também sobre a influência que a ciência e a tecnologia exerciam sobre a sociedade e ainda, a incorporação das questões éticas, políticas, econômicas e ambientais envolvendo o TS. Ao final dos trabalhos de dois TS os alunos elaboraram Laudos Técnicos contendo os resultados para cada amostra e posteriormente apresentaram à turma, em grupos de 3 , por meio de Seminários. Nesses Seminários, também foram promovidas discussões/debates sobre os resultados, seus significados e também a incorporação das questões sociais, éticas, políticas, ambientais e de saúde.

Ainda, durante essas aulas práticas procuramos analisar, por meio de observação, as interações entre alunos e professor, a didática do professor e a postura dos alunos frente à metodologia adotada no desenvolvimento da disciplina. Ao final do semestre letivo aplicamos outros dois questionários: o primeiro com oito questões descritivas (Q2) e o segundo, a versão brasileira do questionário COCTS (PIEARCTS - Q3), além de uma tabela para assinalar as habilidades adquiridas.

Analisaremos neste trabalho três das oito questões do Q2, àquelas que tenham como objetivo conhecer a percepção de cada aluno sobre a abordagem metodológica adotada na disciplina, o desenvolvimento de atitudes e valores, e das habilidades que julgava terem sido proporcionados na disciplina.

O projeto de cooperação internacional - PIEARCTS tem como objetivo investigar as percepções de estudantes e professores brasileiros sobre relações CTS. A adaptação brasileira tem como versão original a elaborada por MANASSERO et al., (2008). A metodologia do PIEARCTS se baseia no uso de questionário de opinião sobre a Ciência, a Tecnologia e a Sociedade (COCTS). A versão brasileira é formada por 30 questões, articuladas em dois questionários anônimos, onde a estrutura foi construída de forma a facilitar a compreensão dos estudantes mais novos e também a considerar que todas as escolhas de respostas têm seus aspectos positivos, sem classificar as respostas como certas ou erradas. A tarefa é considerar os complementos das afirmativas de cada questão a partir de uma escala valorativa de grau de concordância de 1 a 9 , sendo que 1 corresponde a "discordo totalmente", 5 a "indeciso" e 9, "concordo totalmente". Além desses valores, 1 a 9 , há outras duas opções de "não entendo a frase" e "não sei o suficiente para avaliar". Nesse trabalho apresentaremos a análise de duas questões sobre os conceitos que os alunos têm a respeito da Ciência (questão 10111) e a Tecnologia (questão 10211).

\section{DESCRIÇÃO E ANÁLISE DOS DADOS}

O Departamento de Química adota como critério de excelência da qualidade de ensino, para as disciplinas experimentais do Curso Técnico de Química, a divisão das turmas inicialmente de 36 alunos em três subturmas de, em média, 12 alunos cada.

Para um trabalho mais efetivo e acompanhamento mais próximo, o estudo de caso foi realizado observando os trabalhos desenvolvidos por uma subturma de 12 alunos, divididas em duplas, durante todo um semestre, de agosto a dezembro, assistindo a todos os blocos de três aulas semanais, durante 20 semanas. 
Essa subturma estava composta de 7 homens e 5 mulheres, na faixa de 17 a 19 anos, 8 oriundos de escolas públicas e todos escolheram o curso técnico de química por interesse pela área. Lêem jornais com freqüência e, em média, 8 livros por ano, todos têm computadores em casa e 11 deles, com acesso à internet. Dos 12 alunos dessa subturma, 6 tocam algum instrumento musical, como violão, guitarra, teclado, bateria, violino e flauta e 8 declararam ter vontade de fazer cursos de graduação na área (Farmácia, Engenharia Química, Engenharia de Alimentos, Química, Engenharia Metalúrgica). A maioria escolheu com quem quer trabalhar, em duplas, por afinidade e uma pequena minoria, por amizade. Todos esses dados foram coletados a partir das respostas tabeladas do Questionário Q1.

Neste trabalho apresentamos os resultados das observações, do segundo bloco de nove (9) aulas de 50 minutos, distribuídas em três (3) semanas, sobre o TS - Cerveja.

Os alunos maiores de dezoito anos trouxeram seis amostras de Cerveja das marcas escolhidas por eles: Nova Schin, Sol, Kaiser, Itaipava, Antártica e Skol. Todas elas são vendidas em supermercados e de fácil acesso à população.

Para cada um dos oito TS, utilizou-se três semanas, com blocos de três aulas cada, totalizando 450 minutos. Ao longo de todo o semestre durante a observação repetida de blocos semanais de três aulas, (150 minutos), constatamos que o tempo durante essas aulas ficava distribuído da seguinte forma: nos primeiros 70 minutos o professor lançava perguntas desafiadoras aos alunos.

Para o TS - Cerveja, as perguntas foram: Qual é a composição? Quais são os problemas ambientais gerados pelo processo de produção? Qual a diferença entre os tipos de fermentação? Quais são os benefícios e os malefícios trazidos à saúde? Quais os principais produtores? A China é o maior produtor e o menor consumo per capita? Qual é o preço da Cerveja nos vários países? Como é o mercado de importação e de exportação no Brasil? Quantos litros de Cerveja são produzidos no Brasil? Com está a evolução do consumo de Cerveja no Brasil?

À medida que o professor questionava os alunos, motivando-os a responder, também comentava sobre os fatos históricos, o consumo das bebidas no Brasil, as exigências legais, a presença no mercado nacional e internacional e os processos de produção. Logo em seguida, ele explicava algumas características físico-químicas básicas da Cerveja, as análises e detalhava o significado de cada técnica.

Nos próximos 70 minutos, os alunos decidiram juntamente com o professor quais seriam as análises que a turma iria realizar e fizeram o planejamento experimental, em duplas incluindo a pesquisa das toxicidades dos reagentes (Santos, 1999), os resíduos gerados e a sugestão de tratamento. Para o TS - Cerveja, as análises executadas foram: Especificação das amostras, das embalagens, Características organolépticas (cheiro, cor, limpidez), Extrato aparente (refratômetro), Determinação de pH (pHmetro), Turvação (turbidímetro em EBC), Teste de pasteurização (glicofita) e Poder redutor da cerveja (ITT), segundo as normas analíticas do Instituto Adolfo Lutz (1976) e de SCHIAVETO et al., (2002).

Os alunos utilizaram o tempo restante deste bloco de aulas, para os cálculos envolvidos no preparo das soluções. Nas próximas duas semanas, os alunos discutiram os resultados 
encontrados, trocaram informações entre as duplas e com o professor, gerando questionamentos intrínsecos às análises e, em vários momentos, os ampliaram para o dia a - dia, trazendo para o laboratório experiências vivenciadas por fazendeiros, produtores e em algumas vezes, de familiares. Trataram também de aspectos sociais como as causas e consequências do alcoolismo e também de aspectos políticos e econômicos.

Nas observações das aulas constatou-se que a visão que satisfazia os alunos não era somente a que existia nos registros dos procedimentos técnicos. Eles também desenvolveram habilidades processuais e técnicas, usavam da tomada de decisão, enfatizavam a prática para chegar à teoria, buscavam implicações sociais, políticas, ambientais e econômicas dos problemas apresentados, lidavam com problemas verdadeiros nos seus contextos sociais, concordando com LINSINGEN (2007).

A cada final de bloco de três aulas, as bancadas e as vidrarias utilizadas foram limpas e lavadas e os alunos trataram os resíduos gerados, decantando reagentes e neutralizando as soluções residuais, para o TS - Cerveja.

Na última semana os alunos, sob a orientação do professor, dedicaram-se a realizar alguns cálculos de custos das análises, simplificados, considerando apenas volumes e massas dos reagentes utilizados. Ao final dos dois temas sociocientíficos - Cachaça e Cerveja, os alunos e o professor agendaram as apresentações de Seminários, em grupos de três, e a entrega do Laudo Técnico contendo os resultados das análises das amostras de cada dupla.

Durante os Seminários, na apresentação dos alunos pudemos constatar as várias relações entre CTS e os TS escolhidos. No primeiro Seminário os alunos se sentiam motivados a responder a cada uma das perguntas desafiadoras que o professor inicialmente havia feito e ficaram sem respostas.

No Seminário para o TS - Cerveja, os alunos apresentaram: a composição e o teor alcoólico permitido (3 a 8\%); as diferenças no processo de fermentação - originando a cerveja tipo Ale (escura) e do tipo Lager (clara, teor de álcool entre 3 e 3,8\% ); a história da cerveja; o processo geral de produção; a função e os pontos críticos de controle de cada etapa de produção; o mercado mundial; o consumo mundial; o consumo per capita mundial; os preços em vários países; o mercado da cerveja no Brasil; a produção brasileira; a evolução do consumo desde 1995; o consumo per capita brasileiro; a evolução do consumo de refrigerantes e cerveja no Brasil desde 2000 e os impostos no preço da cerveja.

As discussões entre alunos e o professor, aumentavam a cada semana de aula e promoveram uma integração do conhecimento científico com a tecnologia e o mundo social de suas experiências do cotidiano. Relações entre conhecimentos científicos além da sala de aula foram estabelecidas, segundo VIEIRA e MARTINS (2009), buscando compreender a dimensão social da ciência e da tecnologia, bem como suas conseqüências sociais, políticas, éticas, ambientais e para a saúde, como citam AULER (2003); AULER e DELIZOICOV (2001) e COELHO e MARQUES (2007).

Os próximos Seminários apresentados abordaram os resultados das análises das amostras quanto às características físico-químicas. Para a Cerveja os parâmetros foram estabelecidos conforme a legislação vigente do IAL que estabelece os Padrões de Identidade e Qualidade (PIQ's). 
Diante dos resultados encontrados para as seis amostras de Cerveja, os alunos concluíram que Todas as amostras analisadas estavam dentro dos parâmetros estabelecidos pela legislação para o produto, porém para confirmar a qualidade das amostras de Cerveja precisariam realizar os demais testes quantitativos que ficaram faltando.

Do questionário (Q2) aplicado selecionamos, para registro, as respostas mais completas. Em relação à abordagem metodológica os alunos responderam à questão - A abordagem metodológica adotada na disciplina de Química Orgânica Aplicada auxilia para o melhor entendimento do seu papel como cidadão crítico e reflexivo e contribui para o desenvolvimento como futuro profissional da Química? Justifique.

Aluno10 - "Sim, o embasamento teórico, dado antes das práticas, aliado a autonomia nos dada durante o experimento, nos faz desenvolver uma visão crítica que contribui para o papel do cidadão e para o trabalho de um Químico";

Aluno 7 - "Sim, percebi que cada um em sua função contribui com o desenvolvimento da sociedade e no meu desenvolvimento como profissional, auxiliou para ganhar responsabilidade e conhecimento";

Aluno 8 - "Sim, possibilita um pensamento de ciência aplicada em prol de melhorias para a sociedade";

Aluno 9 - "Sim, se tem uma melhor reflexão sobre as práticas e ações realizadas nela";

Aluno 12 - "Sim, adquiri experiência em laboratório e trabalho em equipe, bem como aprendi sobre o meio ambiente e a sociedade".

Obtivemos as respostas a seguir, em relação à ética para a questão - Você percebeu a influência da ética sobre a Ciência e a Tecnologia? Cite em quais momentos.

Aluno 10 - "Sim, nos momentos de análise, a ética é de suma importância, a fim de que os resultados sejam divulgados da maneira correta";

Aluno 7 - "Sim, ao emitirmos um laudo, devemos ter a certeza dos resultados que obtivemos e não podemos manipular estes resultados, já que permitir que produtos fora dos padrões sejam comercializados poderia prejudicar a saúde dos consumidores";

Aluno 8 - "Sim, na verificação da falta de ética de alguns produtores ao comprometerem, conscientemente, a qualidade dos produtos fornecidos ao consumidor";

Aluno 5 - "Sim, na verificação de possíveis alterações nas amostras analisadas e, comprovadamente, feitas de má fê";

Aluno 11 - "Sim, deve-se gerenciar resíduos e ter responsabilidade na análise de produtos".

Nas observações e gravações das aulas percebemos que a abordagem comunicativa entre professor e alunos foi do tipo interativa / dialógica, segundo Scott et al. (2006). Isto significa que o professor e estudantes exploraram idéias, formularam perguntas autênticas e expuseram, consideraram e trabalharam diferentes pontos de vistas.

Para obtermos a percepção dos alunos para esse tipo de interação, solicitamos que respondessem às questões: A metodologia adotada proporcionou maiores interações discursivas entre o professor e os alunos em sala de aula? O equilíbrio entre essa abordagem e a de autoridade adotada pelo professor é benéfico? Qual tem sido o papel do professor? 
Aluno 11 - "Sim, o desenvolvimento do projeto de pesquisa, o tema, possibilita uma visão mais ampla dos métodos analíticos e da sua aplicação na sociedade de uma forma geral"; Aluno 8 - "Sim, com esse tipo de abordagem, o professor atua em uma melhor efetivação do aprendizado e na compreensão dos temas abordados";

Aluno 10 - "Sim, porque com a autonomia que nos é dada, podemos pensar, juntamente com o professor, nos resultados obtidos e o porquê destes. O professor adota uma postura de esclarecedor, deixando-nos raciocinar durante os experimentos, o que contribui para nosso desenvolvimento profissional";

Aluno 7 - "Sim, o professor discute os assuntos em sala, tira nossas dúvidas, gerencia o laboratório e trabalha de forma a dar oportunidade para a participação dos alunos";

Aluno 5 - "Sim, a abordagem é muito benéfica, pois nos propicia uma visão mais ampla a respeito do tema tratado, ou seja, o professor tem o papel de nos guiar em um caminho antes nunca trilhado".

Nas análises das respostas dos alunos a abordagem metodológica adotada possibilitou um embasamento teórico anterior à prática, uma melhor reflexão sobre as práticas e ações realizadas nelas. Ela trouxe uma visão mais ampla e crítica, tornou o aprendizado mais efetivo tendo um significado real para o aluno, concordando com RAMSEY (1993). Potencializou a autonomia e a participação dos alunos, promoveu o trabalho em equipe e contribuiu para a formação do cidadão, corroborando LÓPEZ e CEREZO (1996). E ainda, proporcionou uma integração entre a educação científica, tecnológica e social e, consequentemente, o melhor entendimento do seu papel como cidadão crítico e reflexivo e contribuiu para o seu desenvolvimento como futuro profissional da Química. Percebemos que valores como a ética, atitudes e responsabilidade social também foram desenvolvidas com a abordagem CTS através de TS, conforme registraram SANTOS e MORTIMER (2002 e 2009). Ressaltamos a ampla formação e vasta experiência profissional, além da capacidade do professor como orientador e gerente do laboratório. Ele foi capaz de proporcionar a efetivação do aprendizado e da tomada de decisão, em várias situações geradas durante as aulas.

Na tabela de habilidades, os alunos registram na totalidade (12 respostas) às desenvolvidas nessas aulas práticas, todas são habilidades básicas para práticas educativas com enfoque CTS segundo YAGER (1991). São elas: identificação de problemas com interesse/impacto social; aprendizagem enfocando o futuro; exercício da cidadania ao tentar resolver problemas que eles mesmos identificaram; envolvimento ativo do aluno ao buscar informações úteis; selecionar procedimentos experimentais; lidar com problemas verdadeiros no contexto real; buscar principalmente, implicações sociais dos problemas tecnológicos; construir hipóteses; planejar; comparar e diferenciar; fazer medidas; tirar conclusões; controlar variáveis; comunicar-se; deduzir; interpretar dados; classificar; observar e usar relação tempo/espaço. As habilidades que não foram consideradas totalmente desenvolvidas são: habilidades processuais não muito enfatizadas (75\%); estudo sendo possível na instituição e na comunidade (25\%); ênfase sobre a prática para chegar à teoria; busca principalmente, implicações sociais dos problemas tecnológicos; tecnologia para a ação social; usam números e classificam, todas com $22,5 \%$.

$\mathrm{Na}$ aplicação do questionário PIEARCTS (versão brasileira), a questão 10111 (Definir o que é Ciência é difícil porque ela é complexa e engloba muitas coisas. Mas a Ciência é, PRINCIPALMENTE?) a totalidade dos alunos (12 respostas) concordou que Ciência é, principalmente, um corpo de conhecimentos, como princípios, leis e teorias que explicam o mundo que nos rodeia (matéria, energia e vida) e também, um processo de investigação 
sistemático e o conhecimento resultante. As respostas plausíveis apresentaram alto índice de indicação (11 respostas). Os alunos consideraram as respostas que contêm uma visão de Ciência complexa, de cunho político, social e ambiental; que vai além do caráter exploratório e que o conhecimento científico promove e/ou beneficia a melhoria da qualidade de vida.

Da mesma forma, constatou-se nas respostas dos alunos à questão 10211 (Definir o que é a tecnologia pode ser difícil porque esta serve para muitas coisas. Mas a tecnologia, PRINCIPALMENTE, é,;) que eles perceberam que a Tecnologia está relacionada à investigação e a engenharia. Entenderam que o conhecimento tecnológico resulta na elaboração de instrumentos, ferramentas e aplicações para questões distantes ou próximas de sua vida cotidiana, desde o desenvolvimento de corações artificiais e veículos espaciais até os computadores, celulares, ipods e MP's. Constatou-se que a utilização de TS, apropriados pelo aluno, com enfoque CTS, auxiliou no desenvolvimento de conceito mais amplo de Tecnologia.

Em pesquisa semelhante, ACEVEDO et al. (2005), ao avaliarem a resposta sobre este item, para alunos de graduação, informam que a opção preferida (25\%) confunde a Tecnologia com a aplicação da Ciência. Os mesmos autores, em outra pesquisa (2005b), avaliando a opinião dos professores a partir do mesmo questionário, informam que a opção mais indicada para os iniciantes baseia-se na "visão da Tecnologia como a Ciência aplicada". Seguindo-se do ponto de vista que fornece uma definição mais completa e adaptada do que vem a ser a Tecnologia e da identificação do conhecimento da área pesquisada.

\section{CONSIDERAÇÕES FINAIS}

Ficou evidente que a experiência do professor, suas explicações e o direcionamento metodológico sobre o uso dos elementos CTS contribuíram de forma significativa para a abordagem mais sistemática dos TS. Nesse sentido, os resultados da investigação apontam que a abordagem dos TS em uma perspectiva mais ampla de formação para a cidadania depende da formação das concepções dos professores e da sua prática pedagógica. À medida que, a partir de experiências diversificadas, o professor se permitiu incorporar novas práticas, ele modificou e enriqueceu sua prática em sala de aula, e foi adquirindo autonomia e segurança para a adoção de novas metodologias. Nesse sentido, os resultados evidenciaram que a experiência do professor é condição determinante para o sucesso de suas estratégias em sala de aula.

Os dados obtidos no estudo de caso nos fornecem indicadores de que os TS potencializaram o aumento das interações dialógicas em sala de aula. Ao introduzir a escolha dos TS, os alunos apropriaram-se deles e estabeleceram relações com fatos do cotidiano e discussão. Para que isso acontecesse o professor apresentou formação ampla, postura mais aberta a ouvir os alunos, domínio para gerenciar o laboratório, as análises e o tempo de aulas. O uso de questões desafiadoras contribuiu para que o professor, com experiência em outras áreas de ensino, conseguisse iniciar o movimento dialógico contemplando os horizontes conceituais dos alunos. Os dados indicaram, portanto, que os TS podem ter uma função no ensino de Química, contribuindo para o estabelecimento de mais interações discursivas de natureza dialógica em sala de aula.

Para o TS - Cerveja a análise de dados mostrou que algumas estratégias didáticas, como perguntas desafiadoras, planejamento das análises e construção de fluxograma do trabalho 
contribuíram para o estabelecimento do processo interativo. Associado a isso, a realização de discussões/seminários em grupos, durante e após as aulas, se revelou mais uma estratégia que contribuiu para o envolvimento dos alunos.

A observação das análises do TS e os questionários respondidos reforçaram que a abordagem desses aspectos, além de potencializar o processo de interação em sala de aula, possibilitou o surgimento de situações vivenciais, a discussão de atitudes e valores, e de conceitos de Ciência e de Tecnologia. Várias intervenções sobre situações de seu cotidiano ou de curiosidades e ainda, em relação às atitudes e valores, foram apresentadas pelos alunos e reforçadas pelo professor durante as discussões nas aulas e nos seminários e tiveram desdobramentos econômicos, sociais, políticos e ambientais. Nesse sentido, o professor proporcionou uma abordagem humanística, explorando temas escolhidos pelos alunos e da vivência deles que puderam emergir nas discussões e introduzir questões de valores e atitudes, como a ética e outros. Em relação à Ciência e a Tecnologia, segundo a análise das respostas ao questionário COCTS do PIEARCTS, constatamos que os alunos apresentaram conceitos completos sobre Ciência e Tecnologia, diferentemente dos resultados do projeto internacional onde alunos do ensino médio apresentaram conceitos de senso comum.

Todos esses resultados apontam para a importância da inserção de TS nos currículos do ensino profissional técnico de Química de nível médio, como condição fundamental para o alcance do objetivo da formação da cidadania em cursos que visem à alfabetização científica na perspectiva humanística, reflexiva e crítica; e ainda, mostram o enfoque CTS, como fonte fecunda para a análise do processo educacional das áreas técnicas, com potencialidades transformadoras.

\section{REFERÊNCIAS}

1. ACEVEdo, J. A.; VÁZQUEZ, A. e MASSANERO, M. A.. Papel de la educación CYS en uma alfabetización científica y tecnológica para todas lãs personas. Revista Electrónica de enseñanza de las ciências, v. 9, n. 2, 2003. Disponível em: <http://www.saum.uvigo.est/reec/>. Acesso em: 15 set. 2010.

2. ACEVEDO, J.A.. Cambiando la práctica docente en la enseñanza de las ciencias a través de CTS. Borrador, 13, 26-30, 1996. En línea en Sala de Lecturas CTS+I de la OEI. Recuperado em 11/09, 2010, de <http://www.campusoei.org/salactsi/acevedo2.htm>.

3. ACEVEDO D., J. A.; VÁZQUEZ, A. Á.; ACEVEDO, R. P. e MANASSERO MAS, $\mathrm{M}^{\mathrm{a}}$ A.. Evaluación de creencias sobre ciencia, tecnología y sus relaciones mutuas. CTS Journal, 2(6), 73-99, 2005a. Disponível em <http://www.oei.es/noticias/spip.php?article1274>

4. ACEVEDO D., J. A.; VÁZQUEZ, A. Á.; ACEVEDO, R. P. e MANASSERO MAS, $M^{a}$ A.. Aplicación de una nueva metodología para evaluar las creencias del profesorado sobre La tecnología y sus relaciones con la ciencia. Educación Química, 16(3), 372-382, 2005b.

5. AULER, D.. Alfabetização científico-tecnológica: um novo "paradigma"? Ensaio: pesquisa em educação em ciências, 5 (1), 1-1, 2003.

6. AULER, D. e DELIZOICOV, D.. Alfabetização científico-tecnológica para quê? Ensaio: pesquisa em educação em ciências, 3 (1), 105-115, 2001. 
7. COELHO, J. C. e MARQUES, C. A.. Contribuições freireanas para a contextualização no ensino de Química. Ensaio: Pesquisa em Educação em Ciências, 9 (1), 1-17, 2007.

8. FOUREZ, G.. Crise no ensino de Ciências? Investigações em Ensino de Ciências, 8 (2), 109-123, 2003.

9. INSTITUTO ADOLFO LUTZ - IAL. Normas analíticas do Instituto Adolfo Lutz: métodos químicos e físicos para análise de alimentos e bebidas. 2. Ed., São Paulo: Coordenadoria dos Serviços Técnicos Especializados, Secretaria de estado da Saúde, 1976. 371p.

10. LINSINGEN, I. von. Perspectiva educacional CTS: aspectos de um campo em consolidação na América Latina. Ciência \& Ensino, 1(número especial), 2007.

11. LÓPEZ, J. L. L. e CEREZO, J. A. L. Educación CTS en acción: enseñanza secundaría y universidad. In M. I. G., Garcia, J. A. L., Cerezo e J. L., Lopez (Orgs.). Ciencia, tecnología y sociedad: una introducción al estudio social de la ciencia y la tecnología, (225-252). Madrid: Editorial Tecnos, 1996.

12. MANASSERO, M. A., VÁZQUEZ, A, ACEVEDO D. e J.A., PAIXÃO. COCTS PIEARCTS - Forma 2 @ M.A. Manassero e Á. Vázquez Versão 2.1 - 18/06/2008

13. MANASSERO, M. A. eVÁZQUEZ, A.. Actitudes y valores realcionados com La ciência, La tecnologia y La sociedad em alumnado y profesorado. Implicaciones para La educación de lãs actitudes. Memoria final de investigación. Madrid: MEC-CIDE, 1997.

14. RAMSEY, J.. The science education reform movement: implications for social responsibility. Science Education, 77(2), 235-258, 1993.

15. SANTOS, M. S.. Temas sociocientíficos (Mel) em aulas práticas de Química na educação profissional: uma abordagem CTS. Anais do Encontro Nacional de Didática e Prática de Ensino, Belo Horizonte, MG, Brasil, 15, 2010.

16. SANTOS, M. S.. As Interações Ciência, Tecnologia e Sociedade e seus reflexos nos Encontros sobre Educação Química. Belo Horizonte, 1999. Dissertação de Mestrado, CEFET-MG/UFMG, 1999.

17. SANTOS, M. S.. Fichas de Segurança. Belo Horizonte: CEFET-MG, 1999.

18. SANTOS, W. L. P. dos, MORTIMER, E. F.. Aspectos sociocientíficos em aulas de química e interações em sala de aula. Anais do II Encontro Internacional Linguagem, Cultura e Cognição, Belo Horizonte, MG, Brasil, 2003.

19. SANTOS, W. L. P. dos e MORTIMER, E. F.. Abordagem de aspectos sociocientíficos em aulas de Ciências: possibilidades e limitações. Investigações em Ensino de Ciências, 14(2), 191-218, 2009.

20. SCHIAVETO, Paulo et al. Seminário de Cerveja. Estabilidade Organoléptica. Juatuba. AMBEV, 2002.

21. SCOTT, P. H. ; MORTIMER, E. F. e AGUIAR, O. JR. The tension between authoritative and dialogic discourse: a fundamental characteristic of meaning making interactions in high school science lessons. Science Education, New York, 90(7), 605-631, 2006.

22. VIEIRA, R. M. e MARTINS, I. P. Práticas de professores do Ensino Básico orientadas numa perspectiva CTS-PC, Revista CTS, 79-86, 2009. 
23. YAGER, R. E.. The centrality of practical work in the Science/Technology/Society movement. In: Woolnough, B.(Ed.). Practical Science. England: University Press, 1991. 